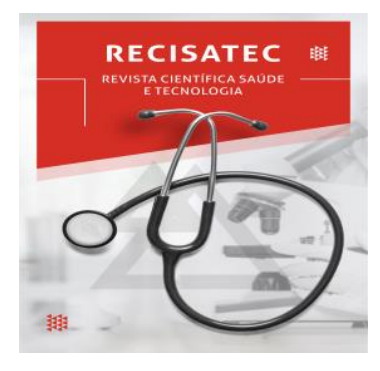

\title{
CONHECIMENTO DOS ACADÊMICOS DA ÁREA DA SAÚDE SOBRE SUPORTE BÁSICO DE VIDA: UMA REVISÃO DE LITERATURA
}

\author{
THE HEALTHCARE ACADEMICS KNOWLEDGE ABOUT BASIC LIFE SUPORT: A LITERATURE \\ REVIEW
}

\section{EL CONOCIMIENTO DE LOS ACADÉMICOS SANITARIOS SOBRE EL SOPORTE VITAL BÁSICO: UNA REVISIÓN DE LA LITERATURA}

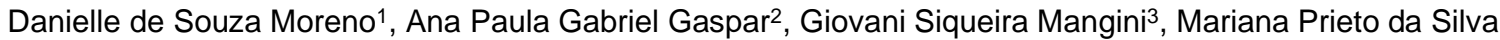
Guedes $^{4}$, Leonardo Lopes Ferreira ${ }^{5}$, Laura C. Pereira Maia ${ }^{6}$

Submetido em: 08/10/2021

e1443

Aprovado em: 18/11/2021

https://doi.org/10.53612/recisatec.v1i4.43

\section{RESUMO}

Introdução: A parada cardiorrespiratória (PCR) é uma das emergências cardiovasculares com elevada prevalência de morbidade e mortalidade. Todo profissional de saúde deve reconhecer os sinais e sintomas de uma PCR, prestar os primeiros cuidados (SBV) e manter-se atualizado sobre o assunto. Objetivo: Descrever o conhecimento dos acadêmicos da área da saúde no suporte básico de vida. Método: Trata-se de uma revisão de literatura de artigos extraídos das bases de dados da Biblioteca Virtual de Saúde LILACS, MEDLINE e SciELO. Foram utilizados os descritores (DeCS) "students", "resuscitation", "knowledge"; e o MeSH, "students", "resuscitation", "practice", "attitude" e "knowledge" de forma isolada e combinada. A busca identificou 876 artigos dos quais apenas 82 apresentavam títulos que tinham proximidade com o tema da pesquisa. Foram selecionados 48 artigos para a leitura integral. A partir destes, 11 artigos foram analisados. Resultados: Os artigos apontam que o conhecimento dos alunos e suas habilidades teóricas e práticas foram insuficientes para realizar uma RCP aceitável e que habilidades podem ser aprimoradas através de treinamentos frequentes, melhorando a retenção de conhecimento e a confiança dos estudantes na prática de RCP. Ainda revelam que os treinamentos devem ser incluídos nas grades curriculares dos cursos da saúde e repetidos ao longo da graduação, mas não houve consenso sobre o tempo de repetição dos treinamentos de SBV. Conclusões: O conhecimento dos estudantes da área da saúde sobre SBV é insuficiente. Ressalta-se a importância do constante aprimoramento das habilidades teórico-prática em SBV ao longo da graduação nos cursos da área da saúde.

PALAVRAS-CHAVE: Suporte básico de vida. Educação continuada. Treinamento. avaliação educacional. Conhecimento.

\footnotetext{
ABSTRACT

1 Universidade Municipal de São Caetano do Sul - USCS

2 Universidade Municipal de São Caetano do Sul - USCS

3 Universidade Municipal de São Caetano do Sul - USCS

4 Universidade Municipal de São Caetano do Sul - USCS

5 Universidade Municipal de São Caetano do Sul - USCS

6 Universidade Municipal de São Caetano do Sul - USCS
}

Introduction: Cardiorespiratory arrest (CRP) prevails as one of the cardiovascular emergencies with a high prevalence of morbidity and mortality. Every health professional must recognize the signs and symptoms of CPA, provide first aid (BLS) and keep up to date on the subject. Objective: To describe the knowledge of health academics in basic life support. Materials and Method: This is a literature review of articles extracted from the databases of the Virtual Health Library LILACS, MEDLINE and 


\title{
RECISATEC - REVISTA CIENTÍFICA SAÚDE E TECNOLOGIA ISSN 2763-8405
}

\author{
CONHECIMENTO DOS ACADÊMICOS DA ÁREA DA SAÚDE SOBRE SUPORTE \\ BÁSICO DE VIDA: UMA REVISÃO DE LITERATURA \\ BASICO DE VIDA: UMA REVISAO DE LITERATURA
Danielle de Souza Moreno, Ana Paula Gabriel Gaspar, Giovani Siqueira Mangini, \\ Danielle de Souza Moreno, Ana Paula Gabrieto da Silva Guedes, Leonardo Lopes Ferreira, Laura C. Pereira Maia
Mariana
}

SciELO. The descriptors (DeCS) "students", "resuscitation", "knowledge" were used; and MeSH, "students", "resuscitation", "practice", "attitude" and "knowledge" in an isolated and combined way. 876 articles of which only 82 had titles that were close to the research topic. 48 articles were selected for full reading. From these, 11 articles were presented. Results: The articles point out that the students' knowledge and their theoretical and practical skills were insufficient to perform an acceptable CPR and that skills can be improved through localized training, improving knowledge retention in addition to the confidence of knowledge in CPR practice. They also reveal that training should be included in the curriculum notes of health courses. and repeated throughout graduation, but there was no consensus on the repetition time of BLS training. Conclusions: The knowledge of students in the health field about BLS is insufficient. The importance of constantly improving theoretical-practical skills in BLS throughout the undergraduate course in health care is emphasized.

KEYWORDS: Basic life support. Continuing education. Training. Educational assessment. Knowledge.

\section{INTRODUÇÃO}

A parada cardiorrespiratória (PCR) é um evento dramático que permanece como uma das emergências cardiovasculares com elevada prevalência de morbidade e mortalidade ${ }^{(1)}$. Ela é definida como a cessação da atividade mecânica cardíaca, confirmada pela ausência de sinais de circulação(2). Quando identificada, é necessário iniciar o mais rápido possível a reanimação cardiopulmonar (RCP) que consiste num conjunto de manobras que auxiliam a restabelecer uma adequada oxigenação, ventilação e circulação, recobrando a função neurológica sem sequelas ${ }^{(3)}$.

Os registros de incidência exata de PCR extra-hospitalar mesmo em países como Estados Unidos e Canadá ainda é desconhecida, mas estima-se aproximadamente 330.000 mortes por ano(4).

Os dados sobre a incidência de PCR no Brasil são escassos( ${ }^{(1)}$. Anualmente, no Brasil, muitas pessoas perdem suas vidas por PCR. Há uma estimativa de 200 mil paradas cardíacas, sendo 100 mil em ambiente extra-hospitalar e 100 mil em ambiente hospitalar ${ }^{(5)}$. A principal determinante das causas de morte por PCR no Brasil e no mundo é a doença cardíaca isquêmica(1).

O rápido reconhecimento de uma PCR é de suma importância para a ação do atendimento a uma emergência, pois a velocidade de assistência e a eficiência na intervenção são essenciais para sobrevida da vítima até chegar ajuda especializada ${ }^{(5)}$. Um indivíduo em parada cardiorrespiratória pode perder de $7 \%$ a $10 \%$ de chances de sobrevivência a cada minuto. Quando a assistência é realizada precocemente com o uso do desfibrilador externo automático (DEA) em até 3 a 5 minutos do início da PCR, a taxa de sobrevivência pode ser bem otimista, podendo chegar até a $85 \%{ }^{(1)}$. Portanto, os aspectos do suporte básico de vida (SBV) que incluem: o reconhecimento imediato da PCR, o contato com o sistema de emergência, o início da RCP de alta qualidade e o uso do DEA no atendimento a uma emergência são fundamentais no desenlace dos casos, como a sobrevida hospitalar sem acometimentos neurológicos ${ }^{(5)}$.

Dentro deste contexto, o SBV deveria ser parte dos esforços comunitários os quais incluem prevenção, reanimação cardiopulmonar, pronto atendimento ao serviço de emergência, suporte 
avançado de vida em pediatria e cuidados pós-ressuscitação. Estas ações fazem parte dos cinco elos da cadeia de sobrevivência da American Heart Association, os quais os três primeiros constituem o SBV(6).

A cadeia de sobrevivência para a parada cardíaca extra-hospitalar consiste em reconhecer a PCR, pedir ajuda, iniciar a RCP e aplicar a desfibrilação, até que o serviço médico de emergência (SME) assuma a responsabilidade e transporte o paciente para um pronto-socorro ${ }^{(3)}$.

Todo profissional de saúde, independente da área de trabalho, desde sua formação, deve saber não só reconhecer os sinais e sintomas da PCR, mas também prestar os primeiros cuidados do SBV e manter-se atualizado sobre o assunto $^{(7)}$.

Em razão de ser a PCR evidenciada como a mais grave emergência clínica, a aplicação das técnicas de SBV é capaz de provocar esgotamento, tensão e fadiga. Deste modo, tem necessidade de habilidades que proporcionem atuar de maneira competente e veloz durante $o$ atendimento ${ }^{(8)}$.

O conhecimento teórico-prático para efetuar o atendimento à vítima de PCR torna-se indispensável para os alunos dos cursos da área da saúde, portanto é de essencial importância instituir nas faculdades e universidades disciplinas pertinentes ao atendimento em urgência e emergência e no atendimento pré-hospitalar (APH) nas matrizes curriculares. Tais ensinamentos proporcionam aos acadêmicos conhecimentos e habilidades de atuação para o atendimento de SBV e o protocolo de RCP com bases nas diretrizes preconizadas pela $A H A^{(9)}$.

A disciplina de primeiros socorros, a qual aborda a temática do suporte básico de vida, deve ser uma parte obrigatória de todos os programas de treinamento para estudantes da área de saúde. Este curso deve ser ministrado no $1^{0}$ ano de graduação e deveriam ser ministrados cursos de atualização pelo menos uma vez por ano, porque o conhecimento adquirido no primeiro ano da disciplina de primeiros socorros pode ser esquecido rapidamente pela falta de praticá-lo(10).

Sendo assim, o objetivo deste trabalho é descrever o conhecimento dos acadêmicos da área da saúde sobre suporte básico de vida.

\section{DESENVOLVIMENTO}

Trata-se de uma revisão integrativa da literatura, que consiste em apresentar uma análise crítica de estudos publicados, a fim de descrever o nível de conhecimento dos acadêmicos da área da saúde sobre o suporte básico de vida e fazer reflexões sobre a realização de futuros estudos nesta área.

A questão de pesquisa delimitada foi: o que se tem publicado sobre a retenção do conhecimento dos acadêmicos da área de saúde sobre o suporte básico de vida?

Para localização e seleção dos estudos foi realizada uma busca na Biblioteca Virtual em Saúde (BVS), US National Library of Medicine (PubMed), Scientific Electronic Library Online (SciELO), Literatura Latino-americana e do Caribe em Ciências da Saúde (Lilacs), Medical Literature 
Analysis and Retrievel System Online (MEDLINE). Os descritores em ciências da saúde (DeCS) utilizados foram: "students", "resuscitation", "knowledge"; e os MeSH foram: "students", "resuscitation", "practice", "attitude" e "knowledge" de forma isolada e combinada, por via do operador booleano "and".

Os critérios de inclusão foram: artigos publicados em português, inglês e espanhol no período compreendido entre janeiro de 2010 a 28 de maio de 2020 e artigos que retratassem as pesquisas realizadas com universitários da área de saúde sobre a conduta diante de uma parada cardiorrespiratória (PCR).

A partir da combinação dos descritores foram obtidos 876 artigos dos quais 608 apresentaram texto completo. Destes, somente 489 estudos foram publicados nos últimos 10 anos. Ainda foram excluídas deste montante as revisões de literatura, monografias, dissertações, notas prévias, editoriais, cartas ao editor, estudos reflexivos e relatos de experiência, totalizando 286 artigos.

Por meio da identificação do título foram excluídos artigos cujo tema não era relacionado ao estudo e publicações duplicadas, resultando em 82 artigos. Em seguida foi realizada a leitura de todos os resumos. Aqueles que apresentaram maior proximidade com o objetivo deste estudo foram selecionados e contabilizados para a leitura integral totalizando 48 artigos. Destes, foram excluídos 15 artigos por não disponibilizarem texto completo e acesso gratuito, 20 artigos por não serem condizentes com o objetivo do estudo e 1 artigo por ter um número de amostra inferior a trinta. Posteriormente, os artigos potencialmente relevantes foram analisados com mais profundidade e inseridos no trabalho de revisão, o que resultou em uma amostra final constituída por 11 artigos. 


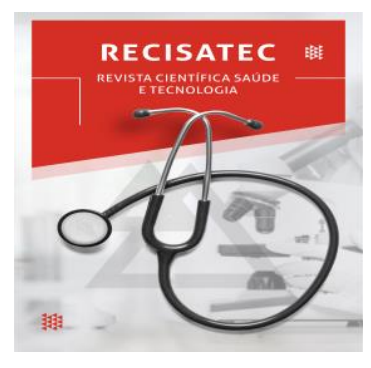

RECISATEC - REVISTA CIENTÍFICA SAÚDE E TECNOLOGIA ISSN 2763-8405

CONHECIMENTO DOS ACADÊMICOS DA ÁREA DA SAÚDE SOBRE SUPORTE
BÁSICO DE VIDA: UMA REVISÃO DE LITERATURA
Danielle de Souza Moreno, Ana Paula Gabriel Gaspar, Giovani Siqueira Mangini,
Mariana Prieto da Silva Guedes, Leonardo Lopes Ferreira, Laura C. Pereira Maia

Figura1 - Fluxograma do processo de seleção dos estudos

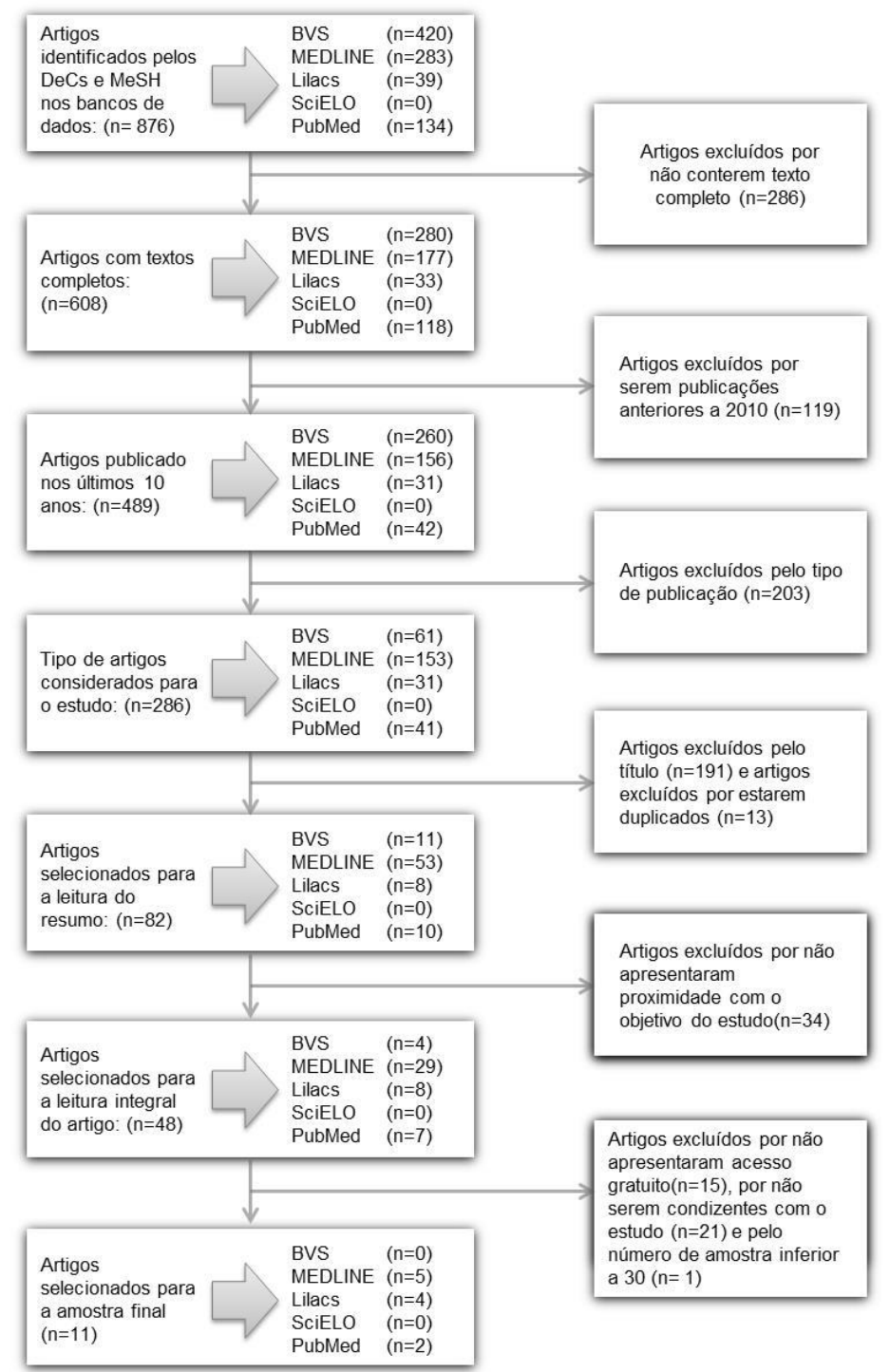

A análise dos dados foi realizada de forma descritiva. Os estudos foram reunidos em grupos, os quais permitiram avaliar as evidências, bem como identificar a necessidade de investigações futuras acerca da temática. Foi utilizado o quadro construído para esse fim, que contemplou os seguintes aspectos: autores/ano de publicação, objetivo, método e conclusão.

Esta revisão foi procedida conforme a Lei 9.610, de 19 de fevereiro de 1998 que rege sobre os direitos morais e patrimoniais de obra criada, como pertencentes ao seu autor, respeitando os direitos autorais e os princípios éticos de combate ao plágio. 


\section{RESULTADOS}

Foram identificados nas buscas 876 artigos os quais foram analisados e a amostra final desta revisão foi constituída por 11 artigos científicos que atenderam aos critérios de inclusão previamente estabelecidos.

Em relação ao tipo de revista, os estudos incluídos na revisão, 4 (36,3\%) foram publicados em revistas de ciências médicas, $1(9,1 \%)$ foi publicado em revista de enfermagem, $1(9,1 \%)$ foi publicado em revista de cardiologia, $1(9,1 \%)$ em revista de psicologia, $1(9,1 \%)$ em revista de trauma e emergência médica, 1 (9,1\%) em saúde pública, 1 (9,1\%) em desenvolvimento humano e 1 (9,1\%) e ciências da saúde.

Quanto ao tipo de delineamento de pesquisa dos estudos avaliados, foram identificados 8 (72,7\%) estudos transversais e 3 estudos (27,3\%) intervencionistas longitudinais.

Em relação ao período de publicação, em 2019 apresentaram 3 (27,3\%); em 2017 houve 2 (18,2\%); o ano de 2016 apresentou 1 (9,1\%); o ano de 2015 houve $2(18,2 \%)$, e nos anos de 2014 , 2013 e 2012 foi apresentado 1(9,1\%) estudo respectivamente.

Evidenciou-se que dos estudos analisados, 4 (36,3\%) foram produzidos por autores brasileiros, $3(27,3 \%)$ foram produzidos por autores de países da Europa, $3(27,3 \%)$ por autores de países da Ásia e $1(9,1 \%)$ estudo foi produzido por autores da África.

O quadro 1 mostra as informações resumidas sobre os estudos: autores/ano de publicação, objetivo, método, e conclusão, para melhor visibilidade dos dados obtidos visando a reflexão crítica acerca da temática investigada. 


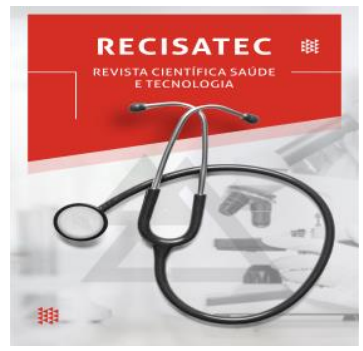

\section{RECISATEC - REVISTA CIENTÍFICA SAÚDE E TECNOLOGIA ISSN 2763-8405}

CONHECIMENTO DOS ACADÊMICOS DA ÁREA DA SAÚDE SOBRE SUPORTE
BÁSICO DE VIDA: UMA REVISÃO DE LITERATURA
Danielle de Souza Moreno, Ana Paula Gabriel Gaspar, Giovani Siqueira Mangini,
Mariana Prieto da Silva Guedes, Leonardo Lopes Ferreira, Laura C. Pereira Maia

Quadro 1 - Apresentação da síntese de estudos incluídos na revisão integrativa

\begin{tabular}{|c|c|c|c|}
\hline $\begin{array}{c}\text { Autor e } \\
\text { Ano }\end{array}$ & Objetivo & Método & Conclusão \\
\hline $\begin{array}{l}\text { Vural et } \\
\text { al., } 2017\end{array}$ & $\begin{array}{c}\text { Avaliar o } \\
\text { conhecimento } \\
\text { em RCP entre } \\
\text { os estudantes } \\
\text { da graduação } \\
\text { em enfermagem } \\
\text { em Faculdades } \\
\text { e Universidades } \\
\text { da Turquia. }\end{array}$ & $\begin{array}{l}\text { Foi aplicado, a } 401 \text { estudantes, um } \\
\text { questionário projetado de acordo } \\
\text { com as diretrizes da AHA de } 2010 \text {, } \\
\text { composto de três partes sobre o } \\
\text { conhecimento em RCP:questões } \\
\text { gerais (importância da RCP na } \\
\text { prática clínica); } \\
\text { precisão da intervenção de RCP e } \\
\text { perguntas direcionadas às } \\
\text { indicações, métodos e eficácia da } \\
\text { RCP. }\end{array}$ & $\begin{array}{l}\text { Os estudantes de enfermagem } \\
\text { possuíam excelente } \\
\text { conhecimento sobre a } \\
\text { importância e o objetivo da } \\
\text { RCP. No entanto, a maioria } \\
\text { deles teve uma pontuação } \\
\text { média em relação à precisão da } \\
\text { RCP e eficácia da RCP, o que } \\
\text { leva a concluir que as } \\
\text { habilidades de RCP em } \\
\text { estudantes de enfermagem } \\
\text { foram insuficientes e que } \\
\text { poderiam ser aprimoradas por } \\
\text { programas de treinamento } \\
\text { certificados que treinam } \\
\text { habilidades básicas de RCP } \\
\text { devendo estes ser um } \\
\text { componente obrigatório em } \\
\text { todos os campos associados à } \\
\text { saúde, como faculdades e } \\
\text { faculdades médicas, } \\
\text { paramédicas e de enfermagem. }\end{array}$ \\
\hline $\begin{array}{l}\text { Owojuyi } \\
\text { gbe et } \\
\text { al.,2015 }\end{array}$ & $\begin{array}{c}\text { Avaliar o efeito } \\
\text { do treinamento } \\
\text { em SBV no } \\
\text { conhecimento } \\
\text { de um grupo de } \\
\text { estudantes de } \\
\text { odontologia da } \\
\text { Nigéria. }\end{array}$ & $\begin{array}{c}\text { Participaram do estudo } 68 \\
\text { estudantes de odontologia. A } \\
\text { avaliação de treinamento pré e } \\
\text { pós-SBV foi realizada com um } \\
\text { questionário validado de } 16 \text { itens } \\
\text { extraído das diretrizes da AHA de } \\
\text { 2010. O questionário consistia em } \\
\text { uma seção de informações } \\
\text { demográficas e uma seção que } \\
\text { avaliava o conhecimento do } \\
\text { entrevistado sobre SBV de } 10 \\
\text { itens. Os questionários foram } \\
\text { aplicados aos estudantes de } \\
\text { odontologia antes e após o } \\
\text { treinamento em SBV. O } \\
\text { treinamento incluiu palestras, } \\
\text { vídeos e demonstrações práticas. }\end{array}$ & $\begin{array}{l}\text { Este estudo demonstrou que o } \\
\text { conhecimento sobre SBV por } \\
\text { um grupo de estudantes de } \\
\text { odontologia da Nigéria antes do } \\
\text { treinamento em RCP era } \\
\text { inadequado. Este estudo } \\
\text { também mostrou a influência } \\
\text { positiva do treinamento no } \\
\text { conhecimento do BLS dos } \\
\text { participantes. }\end{array}$ \\
\hline $\begin{array}{c}\text { Pande } \\
\text { et al., } \\
2014\end{array}$ & $\begin{array}{c}\text { Avaliar o } \\
\text { conhecimento } \\
\text { dos estudantes } \\
\text { de medicina do } \\
\text { primeiro ano } \\
\text { sobre SBV, } \\
\text { treinar os } \\
\text { estudantes em } \\
\text { habilidades de } \\
\text { SBV, estudar o }\end{array}$ & $\begin{array}{l}\text { O procedimento consistiu em } \\
\text { treinamento do corpo docente, } \\
\text { avaliação do conhecimento de } 42 \\
\text { alunos do } 1^{\circ} \text { ano de medicina por } \\
\text { meio de um questionário de } 10 \\
\text { questões baseado na AHA sobre } \\
\text { SBV com objetivo de avaliar, a } \\
\text { sequência correta de eventos } \\
\text { durante a ressuscitação, o local } \\
\text { exato, a profundidade e a taxa de }\end{array}$ & $\begin{array}{c}\text { Os resultados deste estudo } \\
\text { sugerem que o programa } \\
\text { fornece aos alunos } \\
\text { conhecimentos básicos sólidos } \\
\text { e habilidades práticas } \\
\text { adequadas em BLS. A retenção } \\
\text { de conhecimento foi significativa } \\
\text { no segundo ano. Os estudantes } \\
\text { devem ser treinados } \\
\text { novamente, a fim de ajudá-los a }\end{array}$ \\
\hline
\end{tabular}




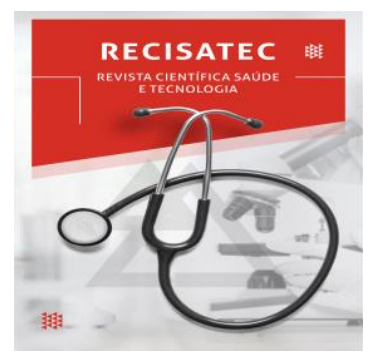

\begin{tabular}{|c|c|c|c|}
\hline & $\begin{array}{c}\text { efeito de } \\
\text { treinamento em } \\
\text { conhecimento e } \\
\text { habilidade e } \\
\text { estudar a } \\
\text { retenção de } \\
\text { conhecimentos } \\
\text { e habilidades } \\
\text { dos alunos em } \\
\text { seu segundo } \\
\text { ano. }\end{array}$ & $\begin{array}{l}\text { compressão torácica, a razão entre } \\
\text { compressão cardíaca e respiração } \\
\text { arterial e a posição pós- } \\
\text { recuperação e um teste de } \\
\text { aquisição de habilidade } \\
\text { processuais diretamente } \\
\text { observadas (DOPS), dividindo o } \\
\text { processo de SBV em } 7 \text { etapas a } \\
\text { serem seguidas corretamente. }\end{array}$ & $\begin{array}{l}\text { reter o conhecimento de SBV e } \\
\text { habilidades satisfatoriamente. }\end{array}$ \\
\hline $\begin{array}{c}\text { Dal et } \\
\text { al., } \\
2013\end{array}$ & $\begin{array}{c}\text { Determinar o } \\
\text { nível de } \\
\text { conhecimento e } \\
\text { habilidades de } \\
\text { ressuscitação } \\
\text { cardiopulmonar } \\
\text { (RCP) de } \\
\text { estudantes de } \\
\text { enfermagem no } \\
\text { norte de Chipre. }\end{array}$ & $\begin{array}{c}\text { Participaram do estudo } 83 \text { alunos } \\
\text { do } 3^{\circ} \text { ano do curso de enfermagem } \\
\text { que estavam participando de um } \\
\text { treinamento de SBV. } \\
\text { Um questionário (pré-teste) foi } \\
\text { aplicado aos alunos antes da } \\
\text { palestra sobre RCP para avaliar o } \\
\text { nível de conhecimento dos } \\
\text { estudantes. } \\
\text { Depois o mesmo questionário e um } \\
\text { formulário de avaliação de } \\
\text { habilidades foi aplicado } 1 \text { mês e } \\
\text { testado novamente em } 6 \text { meses } \\
\text { depois do treinamento. O } \\
\text { questionário e formulário foram } \\
\text { baseados na AHA e ILCOR. } \\
\text { O questionário de avaliação de } \\
\text { conhecimento continha } 23 \\
\text { questões de múltipla escolha sobre } \\
\text { conhecimento em RCP. As } \\
\text { habilidades psicomotoras foram } \\
\text { realizadas em manequim e } \\
\text { observadas por instrutores } \\
\text { certificados em SBV. }\end{array}$ & $\begin{array}{l}\text { As informações teóricas e a } \\
\text { RCP praticada tiveram um } \\
\text { impacto positivo no nível de } \\
\text { conhecimento e habilidades } \\
\text { práticas dos enfermeiros um } \\
\text { mês pós-teste. No entanto, } \\
\text { houve uma diminuição } \\
\text { significativa no nível de } \\
\text { preservação das informações e } \\
\text { a correta aplicação das etapas } \\
\text { da RCP seis meses após o } \\
\text { treinamento. É importante que } \\
\text { as etapas da RCP sejam } \\
\text { executadas corretamente. Os } \\
\text { autores sugerem que o } \\
\text { treinamento teórico e de } \\
\text { habilidades sobre SBV deveria } \\
\text { ser repetido a cada seis meses, } \\
\text { mesmo após a graduação e que } \\
\text { deveria haver mais foco em } \\
\text { garantir a sustentabilidade } \\
\text { desse treinamento durante a } \\
\text { educação. }\end{array}$ \\
\hline $\begin{array}{c}\text { Ravari } \\
\text { et al., } \\
2012\end{array}$ & $\begin{array}{l}\text { Avaliar os } \\
\text { interesses e } \\
\text { conhecimentos } \\
\text { dos estudantes } \\
\text { de medicina em } \\
\text { relação aos } \\
\text { métodos } \\
\text { educacionais na } \\
\text { aprendizagem } \\
\text { da RCP. }\end{array}$ & $\begin{array}{l}\text { Questionário padronizado foi } \\
\text { distribuído entre } 180 \text { estagiários da } \\
\text { Universidade Mashhad de Ciências } \\
\text { Médicas. } 159 \text { estudantes internos } \\
\text { entregaram o questionário que } \\
\text { continha três partes: dados } \\
\text { demográficos, perguntas de } \\
\text { interesse gerais e } 15 \text { questões de } \\
\text { conhecimento sobre RCP. Se } \\
\text { dentro destas } 15 \text { questões } \\
\text { tivessem mais de } 10 \text { respostas } \\
\text { corretas, o grupo seria } \\
\text { categorizado como grupo A, se os } \\
\text { acertos fossem maiores que } 5,0 \\
\text { grupo seria classificado como B, e } \\
\text { se as respostas corretas fossem } \\
\text { menores que } 5 \text { o grupo seria } \\
\text { considerado C. }\end{array}$ & $\begin{array}{c}\text { A educação em RCP é de } \\
\text { interesse da maioria dos } \\
\text { estagiários. Devido à falta de } \\
\text { um local próprio para o } \\
\text { treinamento de RCP (medicina } \\
\text { de enfermaria emergência), o } \\
\text { conhecimento dos estagiários e } \\
\text { suas habilidades práticas foram } \\
\text { insuficientes para realizar uma } \\
\text { RCP aceitável, sugerindo que } \\
\text { uma ala e um currículo } \\
\text { separados são necessários para } \\
\text { treinar melhor a RCP. }\end{array}$ \\
\hline Galvão & Avaliar o & Participaram do estudo 276 & Constatou-se que os alunos \\
\hline
\end{tabular}




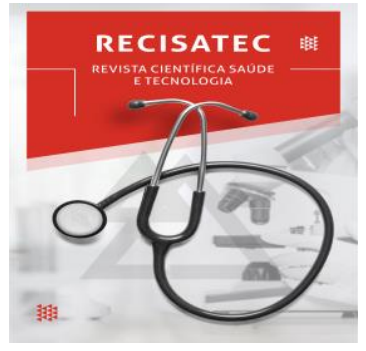

\begin{tabular}{|c|c|c|c|}
\hline $\begin{array}{c}\text { da Silva } \\
\text { et al., } \\
2019\end{array}$ & $\begin{array}{l}\text { conhecimento } \\
\text { dos acadêmicos } \\
\text { da escola da } \\
\text { saúde de uma } \\
\text { universidade } \\
\text { privada sobre o } \\
\text { atendimento de } \\
\text { ressuscitação } \\
\text { cardiopulmonar } \\
\text { no suporte } \\
\text { básico de vida. }\end{array}$ & $\begin{array}{c}\text { estudantes dos cursos de } \\
\text { enfermagem, educação física, } \\
\text { fisioterapia e nutrição do primeiro } \\
\text { semestre letivo de } 2016 \text { de uma } \\
\text { universidade privada que } \\
\text { responderam a um questionário } \\
\text { sobre o tema, dividido em duas } \\
\text { partes: 1. Perfil sociodemográfico, } \\
\text { 2. Questões relacionadas ao } \\
\text { atendimento a PCR }\end{array}$ & $\begin{array}{c}\text { entrevistados em geral } \\
\text { obtiveram desempenho razoável } \\
\text { sobre o conhecimento de RCP, } \\
\text { com destaque para os alunos do } \\
\text { curso de enfermagem que } \\
\text { tiveram um maior número de } \\
\text { correlações positivas no } \\
\text { questionário aplicado. Isso pode } \\
\text { ser resultado de um maior } \\
\text { envolvimento e } \\
\text { comprometimento com a } \\
\text { disciplina. }\end{array}$ \\
\hline $\begin{array}{c}\text { Campos } \\
\text { et al., } \\
2019\end{array}$ & $\begin{array}{l}\text { Avaliar o nível } \\
\text { de } \\
\text { conhecimento } \\
\text { dos estudantes } \\
\text { de Odontologia } \\
\text { da Universidade } \\
\text { Federal de Juiz } \\
\text { de Fora quanto } \\
\text { ao suporte } \\
\text { básico de vida }\end{array}$ & $\begin{array}{l}\text { Questionário contendo questões de } \\
\text { múltipla escolha, aplicado a } 126 \\
\text { alunos, abordando as condutas } \\
\text { para o suporte básico de vida de } \\
\text { acordo com as diretrizes atuais da } \\
\text { American Heart Association. Para } \\
\text { avaliar o nível de conhecimento } \\
\text { foram utilizadas duas categorias } \\
\text { com base no percentual individual } \\
\text { de acertos das questões nível de } \\
\text { conhecimento satisfatório (acertos } \\
\geq 51 \% \text { ) e nível de conhecimento } \\
\text { insatisfatório (acertos } \leq 50 \% \text { ). }\end{array}$ & $\begin{array}{c}\text { Dentre os } 126 \text { estudantes de } \\
\text { Odontologia da Universidade } \\
\text { Federal de Juiz de Fora, 82,5\% } \\
\text { destes apresenta grau de } \\
\text { conhecimento insatisfatório } \\
\text { sobre a atuação no suporte } \\
\text { básico de vida. }\end{array}$ \\
\hline $\begin{array}{c}\text { Felipe } \\
\text { Scipião } \\
\text { Moura } \\
\text { et al., } \\
2016\end{array}$ & $\begin{array}{l}\text { Avaliar o } \\
\text { conhecimento } \\
\text { dos estudantes } \\
\text { de Medicina no } \\
\text { último ano da } \\
\text { graduação } \\
\text { sobre as } \\
\text { diretrizes de } \\
\text { ressuscitação } \\
\text { cardiopulmonar } \\
\text { (RCP) } \\
\text { publicadas em } \\
\text { 2010. }\end{array}$ & $\begin{array}{l}\text { A amostra foi composta por } 217 \\
\text { estudantes do sexto ano de cursos } \\
\text { de Medicina de universidades } \\
\text { brasileiras credenciadas pelo } \\
\text { Ministério da Educação. Um } \\
\text { questionário estruturado com } 27 \\
\text { itens foi utilizado para registrar as } \\
\text { características sociodemográficas } \\
\text { dos participantes, bem como } \\
\text { avaliar o conhecimento das } \\
\text { diretrizes de RCP do ILCOR } \\
\text { (Comitê de Ligação Internacional } \\
\text { de Reanimação) publicadas em } \\
\text { 2010. }\end{array}$ & $\begin{array}{l}\text { A base de conhecimento dos } \\
\text { estudantes de medicina sobre } \\
\text { as técnicas de ressuscitação } \\
\text { cardiopulmonar é baixa. Os } \\
\text { alunos que frequentaram os } \\
\text { cursos do ACLS tiveram uma } \\
\text { melhor base de conhecimento e } \\
\text { maior autoconfiança na } \\
\text { realização de manobras de RCP } \\
\text { do que aqueles que não haviam } \\
\text { frequentado cursos } \\
\text { extracurriculares em RCP. Este } \\
\text { estudo torna evidente a } \\
\text { necessidade de revisar como o } \\
\text { ensino da RCP deve ser } \\
\text { realizado nas faculdades de } \\
\text { medicina, a fim de ter } \\
\text { profissionais médicos } \\
\text { adequadamente preparados } \\
\text { para atender esses pacientes. }\end{array}$ \\
\hline $\begin{array}{c}\text { Tavares } \\
\text { et al., } \\
2015\end{array}$ & $\begin{array}{c}\text { Analisar o } \\
\text { conhecimento } \\
\text { de estudantes } \\
\text { de graduação } \\
\text { em ciências da } \\
\text { saúde em testes } \\
\text { objetivos sobre } \\
\text { suporte básico }\end{array}$ & $\begin{array}{l}\text { Participarão do estudo } 664 \text { alunos } \\
\text { de graduação dos cursos de } \\
\text { Medicina, Enfermagem, } \\
\text { Fisioterapia, Farmácia, Nutrição e } \\
\text { Terapia Ocupacional de todos os } \\
\text { anos de graduação. A coleta de } \\
\text { dados se deu através de um } \\
\text { instrumento na forma de } \\
\text { questionário de testes objetivos }\end{array}$ & $\begin{array}{l}\text { Um indivíduo apenas acertou } \\
\text { além da percentagem ideal } \\
\text { seguida pela American Heart } \\
\text { Association, visto que o restante } \\
\text { tinha conhecimento inepto sobre } \\
\text { suporte básico de vida. } \\
\text { Concluindo assim que ações } \\
\text { referentes ao suporte básico de }\end{array}$ \\
\hline
\end{tabular}




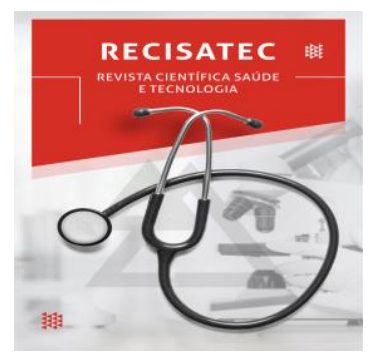

\begin{tabular}{|c|c|c|c|}
\hline & de vida (SBV) & $\begin{array}{l}\text { baseado nos Guidelines da AHA. } \\
\text { Composto por } 20 \text { questões } \\
\text { objetivas. A quantidade de acertos } \\
\text { ideal para análise dos dados foi de } \\
\text { 84\%, baseada nos guidelines e } \\
\text { avaliação do curso BLS da } \\
\text { American Heart Association. }\end{array}$ & $\begin{array}{c}\text { vida sejam introduzidas nos } \\
\text { currículos desde o primeiro ano } \\
\text { de graduação ainda que } \\
\text { necessitando da educação } \\
\text { continuada para melhores } \\
\text { resultados. }\end{array}$ \\
\hline $\begin{array}{c}\text { Méndez } \\
- \\
\text { Martíne } \\
\text { z et al., } \\
2019\end{array}$ & $\begin{array}{l}\text { Investigar o } \\
\text { efeito do } \\
\text { treinamento } \\
\text { sobre Suporte } \\
\text { Básico de vida } \\
\text { (SBV) na } \\
\text { aquisição de } \\
\text { conhecimentos, } \\
\text { habilidades de } \\
\text { RCP e gestão } \\
\text { do Desfibrilador } \\
\text { Externo } \\
\text { Automático } \\
\text { (DEA) em } \\
\text { estudantes de } \\
\text { Ciências da } \\
\text { Saúde. }\end{array}$ & $\begin{array}{l}\text { Foram separados } 112 \text { alunos em } 3 \\
\text { turmas do 1 ano do Curso de } \\
\text { Enfermagem e Fisioterapia. Foi } \\
\text { realizada uma intervenção } \\
\text { educacional teórico-prática de } \\
\text { quatro horas de duração, que } \\
\text { incluiu treinamento em RCP, DEA e } \\
\text { Suporte Básico de Vida (SBV). } \\
\text { Questionário de conhecimento } \\
\text { sobre RCP foi utilizado pré e pós- } \\
\text { teste com } 10 \text { questões, de acordo } \\
\text { com a European Resuscitation } \\
\text { Council (ERC, } 2015 \text { ), com tempo } \\
\text { estimado de } 10 \text { minutos cada. }\end{array}$ & $\begin{array}{l}\text { O treinamento em RCP teórico- } \\
\text { prático foi capaz de resultar na } \\
\text { melhora da aquisição de } \\
\text { conhecimento sobre SBV, uso } \\
\text { do DEA e na aquisição de } \\
\text { habilidades em RCP, não } \\
\text { deixando de lado a necessidade } \\
\text { de retreinamento dos } \\
\text { conhecimentos e habilidades } \\
\text { adquiridos. }\end{array}$ \\
\hline $\begin{array}{c}\text { Maha A. } \\
\text { Al- } \\
\text { Mohaiss } \\
\text { en, } \\
2017\end{array}$ & $\begin{array}{c}\text { Avaliar o } \\
\text { conhecimento e } \\
\text { as atitudes em } \\
\text { relação ao } \\
\text { suporte básico } \\
\text { de vida entre } \\
\text { estudantes } \\
\text { sauditas } \\
\text { mulheres da } \\
\text { área da saúde, } \\
\text { em relação à } \\
\text { faculdade e ao } \\
\text { ano de estudo. }\end{array}$ & $\begin{array}{l}\text { Este estudo envolveu } 2995 \text { alunos, } \\
\text { de cinco faculdades de saúde da } \\
\text { Arábia Saudita, participando os } \\
\text { cursos de Medicina, Odontologia, } \\
\text { Enfermagem, Farmácia e Ciências } \\
\text { da Saúde e Reabilitação. Foi } \\
\text { aplicado um questionário final } \\
\text { autoaplicável continha } 27 \text { questões } \\
\text { que avaliam o conhecimento e as } \\
\text { habilidades do BLS (21 questões } \\
\text { de múltipla escolha) e atitudes em } \\
\text { relação ao BLS (seis questões de } \\
\text { múltipla escolha). A importância do } \\
\text { estudo foi explicada enquanto o } \\
\text { questionário era distribuído. }\end{array}$ & $\begin{array}{c}\text { Embora este estudo tenha } \\
\text { medido o conhecimento e as } \\
\text { atitudes em BLS, não avaliou as } \\
\text { habilidades reais de BLS entre } \\
\text { os alunos. Apesar das atitudes } \\
\text { positivas em relação ao } \\
\text { treinamento em SBV, muitos } \\
\text { alunos nunca haviam recebido } \\
\text { treinamento, assim, foi } \\
\text { observado também níveis } \\
\text { baixos de conhecimento entre } \\
\text { os alunos treinados. Sendo } \\
\text { aconselhável a implementação } \\
\text { do treinamento em currículos } \\
\text { universitários, preferencialmente } \\
\text { no primeiro ano e também, } \\
\text { cursos de atualizações. }\end{array}$ \\
\hline
\end{tabular}

\section{DISCUSSÃO}

Todas as formas de educação profissional têm em comum a meta de preparar estudantes para uma prática resolutiva e responsável a serviço de outrem, portanto, profissionais em treinamento devem dominar uma grande quantidade de teoria e de conhecimento. A avaliação de seus esforços, contudo, não será o que eles sabem, mas o que eles são capazes de fazer ${ }^{(11)}$ 


\section{RECISATEC - REVISTA CIENTÍFICA SAÚDE E TECNOLOGIA ISSN 2763-8405}

CONHECIMENTO DOS ACADÊMICOS DA ÁREA DA SAÚDE SOBRE SUPORTE BÁSICO DE VIDA: UMA REVISÃO DE LITERATURA Danielle de Souza Moreno, Ana Paula Gabriel Gaspar, Giovani Siqueira Mangini, Mariana Prieto da Silva Guedes, Leonardo Lopes Ferreira, Laura C. Pereira Maia

As habilidades práticas dos estudantes no que se refere ao atendimento à vítima de parada cardíaca (PCR) súbita, o conhecimento escasso ou o conhecimento incorreto sobre SBV, pode comprometer o socorro prestado à vítima(12).

Assim, a aquisição do conhecimento e manutenção das habilidades adquiridas está diretamente relacionada às técnicas de ensinamento empregadas. Estudos concordam que a melhor maneira para aquisição e manutenção dessas habilidades é com aulas práticas ${ }^{(13,14)}$.

Miotto et al. ${ }^{(13)}$ demonstraram que treinamento somente teórico não foi capaz de produzir RCP de boa qualidade, principalmente manobras como abertura de vias aéreas, posicionamento correto das mãos, compressão adequada do tórax, ventilação e ciclos de ventilação compressão adequados $^{(13)}$.

Assim, a maioria dos estudos apresentados nesta revisão (72,7\%) constatou que o conhecimento dos alunos e suas habilidades teóricas e práticas foram insuficientes para realizar uma RCP aceitável(15-22).

Segundo AHA 2015(3), os cuidados de alta qualidade prestados às vítimas de PCR devem ser baseados em treinamentos baseados em evidências, ou seja, em princípios educacionais pautados por pesquisas científicas e que traduzam o conhecimento em prática. Em suas principais recomendações estão: o uso de dispositivo de feedback para RCP que ajuda na aprendizagem da habilidade psicomotora da RCP; o uso de manequins de alta fidelidade, mas não desmerecendo o manequim padrão na impossibilidade do uso do primeiro; aprendizagem de habilidades de SBV através de recursos de autoaprendizagem (em vídeo e computador); treinamento prévio que reforça o aprendizado das habilidades e desenvolve a confiança necessária para aplicar a RCP diante de uma inesperada PCR; treinamento do uso do DEA (embora o uso do DEA não deva ser limitado aos indivíduos treinados) e preparação de pré-curso, que inclui revisão adequada de informações do conteúdo, testes on-line/pré-curso e/ou a prática das habilidades técnicas de $\mathrm{SBV}^{(3)}$.

Em relação à recomendação sobre o ciclo de requalificação a cada dois anos não ser o ideal, a AHA 2015 ainda não determinou o prazo ideal para a reciclagem, mas entende que para profissionais da saúde, treinamentos mais frequentes e curtos reforçam as habilidades de suporte básico de vida, além da confiança em aplicá-las ${ }^{(3)}$.

Entre os diversos estudos, não há um consenso sobre o tempo de repetição dos treinamentos de SBV. Owojuyigbe et al e Pande et al. ${ }^{(16,23)}$ recomendam a incorporação do treinamento em SBV no currículo médico e de odontologia respectivamente, no $1^{\text {a }}$ ano com reforço da habilidade em todos os anos da graduação. Já Dal et al. ${ }^{(24)}$ alega que o treinamento teórico e de habilidades devem ser repetidos a cada seis meses, mesmo após a graduação(24).

É necessário praticar substancialmente para que se possam atingir os objetivos de habilidade e desempenho psicomotor ${ }^{(25)}$.

Pande et al. ${ }^{(23)}$ avaliaram o conhecimento de estudantes de medicina do primeiro ano, aplicando um pré-teste, um pós-teste com um intervalo de 2 semanas e um segundo pós-teste após 
um ano do treinamento e constataram que houve melhoria das habilidades dos alunos e significativa retenção de conhecimento, além do aumento de confiança destes alunos no segundo ano de medicina para aplicar $\mathrm{RCP}^{(23)}$. Dal et al. ${ }^{(24)}$ fizeram um estudo semelhante com alunos do terceiro ano de enfermagem, aplicando um pré-teste, um pós-teste um mês depois do treinamento de SBV e um segundo pós-teste 6 meses depois ${ }^{(24)}$. Os resultados mostraram que houve uma melhora do conhecimento após um mês do treinamento e um declínio da retenção do conhecimento seis meses depois, porém em relação ao pré-teste, tanto o resultado do primeiro pós-teste (um mês depois) quanto do segundo pós-teste (seis meses depois) foram superiores ao pré-teste, demostrando que mesmo que haja uma perda de conhecimento após um determinado tempo, existe uma influência positiva do treinamento que eleva o nível de conhecimento dos estudantes ${ }^{(16,22,26)}$.

Tavares, Pande, Dal, e Méndez-Martínez et al. ${ }^{(21,23,24,27)}$ ressaltaram que a repetição efetiva de treinamentos em SBV nos seguintes anos impactaria positivamente na retenção de conhecimento dos estudantes sobre $\mathrm{o}$ assunto ${ }^{(21,23,24,27)}$.

Segundo Moura et al. ${ }^{(20)}$, os alunos que tinham curso de suporte avançado de vida, tiveram uma melhor base de conhecimento e uma maior autoconfiança na realização da RCP, estes comparados aos alunos que não tinham cursos extracurriculares em $\operatorname{RCP}^{(20)}$, o que Mohammed acaba observando diferença insignificante em relação à atitude ${ }^{(28)}$.

Tavares et al. e Maha ${ }^{(21,22)}$, relatam que alunos com conhecimento prévio e adquiridos na faculdade, consequentemente adquiram resultados melhores quando comparados à alunos sem conhecimento prévio(21,22), corroborando com os autores Vural e Ravari et al.(15,17), que destacaram que o conhecimento dos alunos sobre RCP, teria maior desempenho se acompanhado de um treinamento prévio(15,17).

Já Maha(22) em seus resultados, obteve a informação de que alunos sem conhecimento prévio tinham maior interesse em cursos sobre o suporte básico de vida do que alunos que já obtinham o conhecimento(22). Ravari et al. ${ }^{(17)}$ também afirma que a prática eficaz na realização de RCP é de interesse dos alunos da saúde, no entanto, viu-se necessário um local próprio para promover adequado treinamento de RCP no SBV durante a graduação(17).

Maha e Pande ${ }^{(22,23)}$ concluem que é aconselhável que o treinamento em SBV seja incorporado à grade curricular dos universitários, preferencialmente para alunos do primeiro ano ${ }^{(22,23)}$, já Vural ${ }^{(15)}$, cita que deve ser obrigatório o treinamento de habilidades básicas em RCP em todas as áreas da saúde, por estarem em constante contato e à frente de uma inesperada situação.

Visando o aumento da retenção de conhecimento dos acadêmicos, Machado et al. ${ }^{(29)}$ relata que muitas universidades já incluem o treinamento nos primeiros anos acadêmicos junto ao uso de tecnologias educacionais ${ }^{(29)}$, portanto Kopacek et al. ${ }^{(30)}$ adverte que cursos de atualização constantes devem ser introduzidos ao longo da formação( ${ }^{(30)}$. Campos et al. ${ }^{(19)}$ sugere a inclusão de uma disciplina obrigatória de SBV na grade curricular dos cursos da saúde, composta por uma equipe 


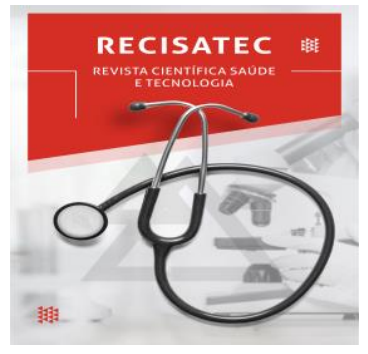

Mariana Prieto da Silva Guedes, Leonardo Lopes Ferreira, Laura C. Pereira Maia multiprofissional e destaca também, a importância do ensino continuado por meio de projetos de extensão, treinamento profissional, eventos e palestras sobre temas afins e agregantes ao SBV. ${ }^{(19)}$.

\section{CONCLUSÃO}

O conhecimento dos estudantes da área da saúde sobre SBV é insuficiente. Ressalta-se assim, a importância do constante aprimoramento das habilidades teórico-prática em SBV ao longo da graduação, visto que tais estudantes se tornarão profissionais da área de saúde podendo se deparar com situações que necessitem de uma intervenção eficaz em SBV.

\section{REFERÊNCIAS}

1. Bernoche C, Timerman S, Polastri TF, Giannetti NS, Siqueira AWDS, Piscopo A, et al. Atualização da diretriz de ressuscitação cardiopulmonar e cuidados cardiovasculares de emergência da sociedade brasileira de cardiologia - 2019. Arq Bras Cardiol. 2019;113(3):449-663.

2. Jacobs I, Nadkarni V, Bahr J, Berg RA, Billi JE, Bossaert L, et al. Cardiac arrest and cardiopulmonary resuscitation outcome reports: Update and simplification of the Utstein templates for resuscitation registries. A statement for healthcare professionals from a task force of the International Liaison Committee on Resusci. Circulation. 2004;110(21):3385-97.

3. Association AH. Atualização das Diretrizes de RCP e ACE: Destaques da American Heart Association 2015. Am Hear Assoc [Internet]. 2015; Available from: https://eccquidelines.heart.org/wpcontent/uploads/2015/10/2015-AHA-Guidelines-Highlights-Portuguese.pdf

4. Stiell IG, Brown SP, Nichol G, Cheskes S, Vaillancourt C, Callaway CW, et al. What is the optimal chest compression depth during out-of-hospital cardiac arrest resuscitation of adult patients? Circulation. 2014;130(22):1962-70.

5. Gonzalez MM, Timerman S, de Oliveira RG, Polastri TF, Dallan LAP, Araújo S, et al. I guideline for cardiopulmonary resuscitation and emergency cardiovascular care - Brazilian society of cardiology: Executive summary. Arq Bras Cardiol. 2013;100(2):105-13.

6. Berg MD, Schexnayder SM, Chameides L, Terry M, Donoghue A, Hickey RW, et al. Part 13: Pediatric basic life support: 2010 American Heart Association Guidelines for Cardiopulmonary Resuscitation and Emergency Cardiovascular Care. Circulation. 2010;122(SUPPL. 3):862-75.

7. Colet D, Griza GL, Fleig C do N, Conci RA, Sinegalia AC. Acadêmicos e profissionais da odontologia estão preparados para salvar vidas? Rfo. 2011;16(1):25-9.

8. Aparecida FSD, Floriano GSE, Rodrigues CMRBA. Ensino Em Enfermagem E Tomada De Decisão: Guideline 2015-2010 Teaching in Nursing and Decision Making: Guideline 2015-2010. 2013;6(3):83-95.

9. Boaventura AP, Miyadahira AMK. Programa de capacitação em ressuscitação cardiorrespiratória com uso do desfibrilador externo automático em uma universidade. Rev Gaúcha Enferm. 2012;33(1):191-4.

10. Tan ECTH, Hekkert KD, Van Vugt AB, Biert J. First aid and basic life support: A questionnaire 


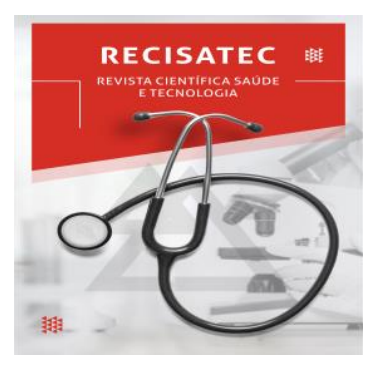

survey of medical schools in the Netherlands. Teach Learn Med. 2010;22(2):112-5.

11. Saidi F. American medical education 100 years after the flexner report. Arch Iran Med. 2007;10(1):131-3.

12. Pergola AM, Araujo IEM. O leigo e o suporte básico de vida TT - El lego y el soporte básico de vida TT - Laypeople and basic life support. Rev da Esc Enferm da USP [Internet]. 2009;43(2):33542. Available from: http://www.scielo.br/scielo.php?script=sci arttext\&pid=S008062342009000200012\&lang=pt\%0Ahttp://www.scielo.br/pdf/reeusp/v43n2/a12v43n2.pdf\%0Ahttp://ww w.scielo.br/pdf/reeusp/v43n2/en a12v43n2.pdf

13. Miotto HC, Ribeiro F, Ribeiro CV, Goulart EMA, Vieira C. Efeito na ressuscitação cardiopulmonar utilizando treinamento teórico versus treinamento teórico-prático. Arq Bras Cardiol. 2010;95(3):328-31.

14. Capone PL, Lane JC, Kerr CS, Safar P. Life supporting first aid (LSFA) teaching to Brazilians by television spots. Resuscitation. 2000;47(3):259-65.

15. Vural M, Koşar MF, Kerimoğlu O, Kızkapan F, Kahyaoğlu S, Tuğrul S, et al. Cardiopulmonary resuscitation knowledge among nursing students:A questionnaire study. Anatol $\mathrm{J}$ Cardiol. 2017;17(2):140-5.

16. Owojuyigbe A, Adenekan A, Faponle A, Olateju S. Impact of basic life support training on the knowledge of basic life support in a group of Nigerian Dental Students. Niger Postgrad Med J. 2015;22(3):164.

17. Ravari H, Abrishami M, Ghezel-Sofla M, Vahedian-Shahroodi M, Abrishami M. Knowledge of Iranian medical interns regarding Cardio-Pulmonary Resuscitation. Trauma Mon. 2012;17(1):242-4.

18. Galvão SBT, Andrade EDS, Paiva RDM, Neto AV de L, Lucas SHL, Dos Santos WN. The knowledge of health academics with regards to cardiopulmonary resuscitation in basic life support / Conhecimento de acadêmicos da saúde sobre ressuscitação cardiopulmonar no suporte básico de vida. Rev Pesqui Cuid é Fundam Online. 2019;11(4):957.

19. Miranda CAC, Souza PANM, Gonçalves LIC, Nogueira SB, Carvalho MF. Nível de conhecimento sobre suporte básico de vida dos estudantes de odontologia. HU Rev. 2019;45(2):1706.

20. Moura FS, Carvalho FV de, Martins M do C de C, Vasconcelos GM, Mello PMV de C. Knowledge of Guidelines for Cardiopulmonary Resuscitation among Brazilian Medical Students. Rev Bras Educ Med. 2016;40(1):77-85.

21. Tavares LFB, Bezerra IMP, Oliveira FR, Sousa LV de A, Raimundo RD, de Sousa EC, et al. Conhecimento de estudantes de graduação em ciências da saúde em testes objetivos sobre suporte básico de vida. J Hum Growth Dev. 2015;25(3):297-306.

22. Al-Mohaissen MA. Knowledge and attitudes towards basic life support among health students at a Saudi women's university. Sultan Qaboos Univ Med J. 2017;17(1):e59-65. 


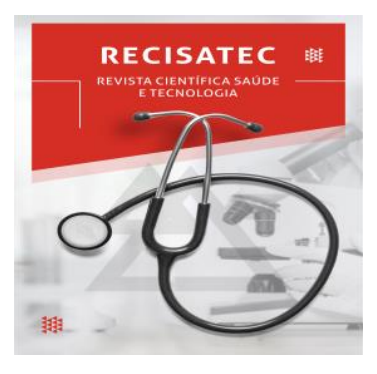

23. Pande S, Pande S, Parate V, Pande S, Sukhsohale N. Evaluation of retention of knowledge and skills imparted to first-year medical students through basic life support training. Am J Physiol Adv Physiol Educ. 2014;38(1):42-5.

24. Dal U, Sarpkaya D. Knowledge and psychomotor skills of nursing students in North Cyprus in the area of cardiopulmonary resuscitation. Pakistan J Med Sci. 2013;29(4):1-6.

25. Einspruch EL, Lynch B, Aufderheide TP, Nichol G, Becker L. Retention of CPR skills learned in a traditional AHA Heartsaver course versus 30-min video self-training: A controlled randomized study. Resuscitation. 2007;74(3):476-86.

26. Becker T, Zanchim MC, Becker T, Compher C, Chittams J, Sammarco T, et al. Cumulative Fluid Balance and Outcome of Extubation: A Prospective Observational Study from a General Intensive Care Unit. Indian J Crit Care Med [Internet]. 2018;33(1):28-33. Available from: http://dx.doi.org/10.1016/i.clnesp.2016.04.030\%0Ahttp://dx.doi.org/10.1016/i.clnu.2014.07.008\%0Ahtt p://dx.doi.org/10.1016/i.clnu.2016.08.004\%0Ahttp://dx.doi.org/10.1016/j.jcrc.2016.09.007\%0Ahttp://dx. doi.org/10.1038/s41430-017-0008-7\%0Ahttp://dx.doi.org/1

27. García-Suárez M, Méndez-Martínez C, Martínez-Isasi S, Gómez-Salgado J, FernándezGarcía D. Basic life support training methods for health science students: A systematic review. Int J Environ Res Public Health. 2019;16(5).

28. Mohammed Z, Arafa A, Saleh Y, Dardir M, Taha A, Shaban H, et al. Knowledge of and attitudes towards cardiopulmonary resuscitation among junior doctors and medical students in Upper Egypt: cross-sectional study. Int J Emerg Med. 2020;13(1):4-11.

29. Rene V, Machado N, González N, Arelys C, Hernández F. Retención de conocimientos sobre reanimación cardiopulmonar básica en estudiantes de medicina de Cienfuegos (2017-2018). Medisur. 2018;16(6):886-94.

30. Kopacek KB, Anna DL, Dopp JM, Vardeny O, Sims JJ. Pharmacy students' retention of knowledge and skills following training in automated external defibrillator use. Am J Pharm Educ. 2010;74(6):1-6. 